\title{
Preparation and characterization of Jatropha oil-based Polyurethane as non-aqueous solid polymer electrolyte for electrochemical devices
}

\begin{abstract}
Jatropha-oil based polyurethane is one of the initiative for replacing conventional petroleum based polyurethane. The vegetable oil-based polyurethane is more cost-effective and synthesize from renewable resources. Polyurethane was synthesized through prepolymerization method between jatropha oil-based polyol and diphenylmethane 4, 4'diisocyanate, (MDI) in inert condition. Then, lithium perchloride ion $\left(\mathrm{LiClO}_{4}\right)$ was added to the polyurethane system to form electrolyte film via solution casting technique. The polymer electrolytes were prepared by varying the amount of $\mathrm{LiClO}_{4}$ ion $10 \mathrm{wt} . \%$ to $30 \mathrm{wt}$. $\%$. The highest conductivity is achieved at $25 \mathrm{wt} . \%$ of $\mathrm{LiClO}_{4}$ salt content, which is $1.29 \times 10^{-4} \mathrm{~S} / \mathrm{cm}$ at room temperature $30{ }^{\circ} \mathrm{C}$. The FTIR results showed the shifting of carbonyl group $(\mathrm{C}=\mathrm{O})\left(1750 \mathrm{~cm}^{-1}-1730 \mathrm{~cm}^{-1}\right)$, ether and ester group $(\mathrm{C}-\mathrm{O}-\mathrm{C})\left(1300 \mathrm{~cm}^{-1}\right.$ $\left.1000 \mathrm{~cm}^{-1}\right)$ and amine functional groups $(\mathrm{N}-\mathrm{H})\left(1650 \mathrm{~cm}^{-1}-1500 \mathrm{~cm}^{-1}\right)$ in polyurethane electrolytes from the blank polyurethane shows that oxygen and nitrogen atom acts as electron donor in the electrolytes system. It also confirmed that the intermolecular reaction had occurred in the electrolytes system. While, the XRD analysis showed the semi-crystalline properties of polyurethane have been reduced to amorphous phase upon the increasing addition of lithium ion. SEM results revealed the morphology analysis of the polyurethane electrolytes. There is homogenous and smooth surface in polyurethane and the dissociation of salt was observed after the addition of salt indicates there was interaction between salt and the polymer host.
\end{abstract}

Keyword: Jatropha oil-based polyurethane; Polyol; Solid polymer electrolyte; Ionic conductivity 